\title{
FURTHER EXPERIMENTS ON THE ADAPTATION OF MAHONEY, TYPE 1, POLIOMYELITIS VIRUS TO SUCKLING MICE
}

\author{
BY GOLDA SELZER AND M. BUTCHART \\ C.S.I.R. and U.C.T. Virus Research Unit, Department of Pathology, \\ University of Cape Town, South Africa
}

(With 3 Figures in the Text)

After $\mathrm{MEF}_{1}$ Type 2 poliomyelitis virus had been adapted to suckling mice to cause consistently high incidence of early paralysis by mouse-to-mouse passage (Selzer, Sacks \& van den Ende, 1952), an attempt was made to adapt Mahoney, Type 1, poliomyelitis virus by a similar technique but this was unsuccessful (Selzer, 1957).

To-and-fro passage of Mahoney virus between monkey kidney-tissue culture and suckling mouse brain (TC-M) was then tried. In the initial work (Fig. 1, TC-M passages 1-6) early paralysis was produced in $44-88 \%$ of the mice in groups inoculated directly from tissue culture of the Mahoney virus. However, inoculation of brain and cord suspensions from these paralysed mice into further sucklings, without intermediate passage through tissue culture, failed to cause paralysis except in an occasional animal (Selzer, 1957).

This report describes the extension of that work. The Mahoney virus has been established in a long-continued series of uninterrupted mouse-to-mouse passages to produce paralysis in $90-100 \%$ of suckling mice within $48-72 \mathrm{hr}$. after inoculation.

\section{MATERIALS AND METHODS}

Virus

The virus used was the Mahoney strain present at a titre of $10^{6.3} \mathrm{TCID}_{50} / \mathrm{ml}$. in the 7 th tissue-culture passage after six to-and-fro TC-M passages (Fig. 1).

\section{Tissue culture}

Each culture tube received $6 \times 10^{5}$ monkey kidney-tissue cells, prepared by the method of Melnick, Rappaport, Banker \& Bhatt (1955), in 1 ml. nutrient of Hanks' solution with $0.5 \%$ lactalbumin hydrolysate and $5 \%$ horse serum.

Titrations of virus in tissue-culture fluids and in mouse brain and cord suspensions were performed by preparing serial tenfold dilutions of the tissue-culture fluids and suspensions in Hanks' solution and inoculating $0.1 \mathrm{ml}$. of each dilution into three tissue-culture tubes. The cells were observed daily for 7 days for cytopathic changes. Titration end-points were expressed as $\log \mathrm{TCID}_{50} / \mathrm{ml}$.

Neutralization tests were performed with Brunhilde, Type 1, monkey poliomyelitis immune serum and $\mathrm{MEF}_{1}$, Type 2, mouse poliomyelitis immune serum. Aliquots of sera, diluted 1 in 5, were added to an equal volume of fluid containing 
$100 \mathrm{TCID}_{50}$ Mahoney virus, left for $1 \mathrm{hr}$. at room temperature and then inoculated into tissue-culture tubes which were observed daily for 7 days for cytopathic changes.

$$
\text { Mice }
$$

The Onderstepoort strain of albino mice bred in this laboratory was used. The mice were inoculated intracerebrally when 4-5 days old, each suckling receiving $0.2 \mathrm{ml}$. of either tissue-culture fluid or brain and cord suspension.

Brains and cords of paralysed mice were harvested, pooled and ground with glass powder. A $10 \%$ suspension of this material in Hanks' solution containing $10 \%$ rabbit serum was spun at 3000 r.p.m. for $1 \mathrm{hr}$. in a refrigerated centrifuge, and the supernatant fluid used for passage either to tissue culture or to further sucklings and for titration in tissue culture.

A tenfold concentrate of the $10 \%$ brain and cord suspension was used in the first fourteen mouse-to-mouse passages following the 9th TC-M passage. This concentrate was prepared by ultracentrifuging the $10 \%$ suspension at 30,000 r.p.m. for $90 \mathrm{~min}$. and redispersing the pellet in one-tenth the original volume.

\section{Adaptation process}

Starting from the 7th tissue culture (Fig. 1), passages were made seriatim to:

(i) A group of mice, from which paralysed sucklings' brains and cords were harvested on the 4th post-inoculation day and a $10 \%$ suspension of the pooled material passed to

(ii) a further group of 100 mice. Only two of these became paralysed within 8 days. One suckling became paralysed in only a hindlimb within $24 \mathrm{hr}$. and the other manifested paralysis the following day. Brain and cord suspension from the former suckling alone was the parent material for the subsequent passage. A $10 \%$ preparation was inoculated into

(iii) the 8th tissue culture from which the next passage was to

(iv) mice for a series of seven successive mouse-to-mouse passages in groups of between twenty and eighty-six sucklings depending on the availability of litters. The results of these passages are given in Fig. 2. After this a return was made to

(v) 9 th and final tissue culture which was passed back to

(vi) mice in a series of seventy-five uninterrupted mouse-to-mouse passages made to date. In the first fourteen of these (Fig. 3) the inoculum used was the tenfold-concentrated preparation, thereafter the usual $10 \%$ suspension was used. Periodically the original material, the concentrate and the concentrate redispersed in a volume of normal saline equal to the original volume, were inoculated into groups of mice and the results compared.

\section{RESULTS}

Fig. 1 shows the results of passages in the first stage of the attempt at adaptation. In previously reported work (Selzer, 1957) 5th and 6th TC-M passages caused paralysis in 58 and $88 \%$ of sucklings, but passages from these to further sucklings paralysed only 8 and $6 \%$, respectively, and further subinoculations failed to produce paralysis in any. 
The 7th TC-M passage paralysed $58 \%$ of the mice, and virus titre in these was $10^{6.5} \mathrm{TCID}_{50} / \mathrm{ml}$. of $10 \%$ brain emulsion. This material inoculated directly into another group of mice caused paralysis in only $2 \%$. The material from the single

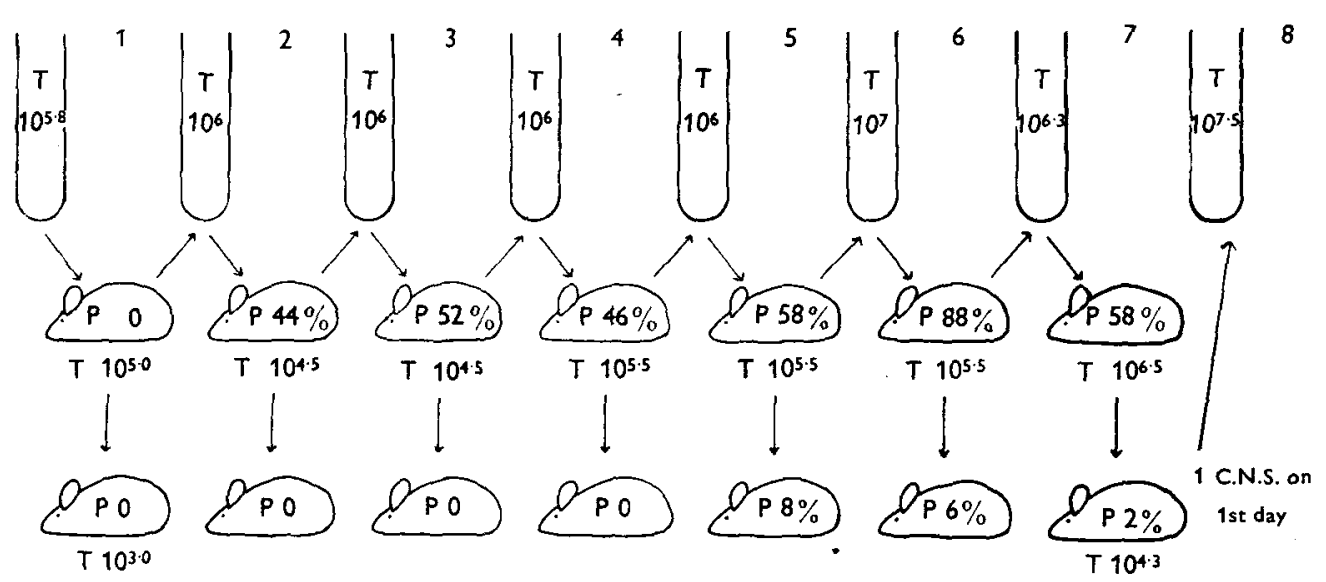

Fig. 1. Adaptation of Mahoney, Type 1, poliovirus to suckling mice. To-and-fro tissue culturemouse (TC-M) passages 1-8, showing percentages of mice paralysed within 4 days of inoculation $(\mathrm{P})$ and the virus titre of paralysed mice (T). c.N.S. on first day $=$ mice paralysed within 24 hr. (see text).

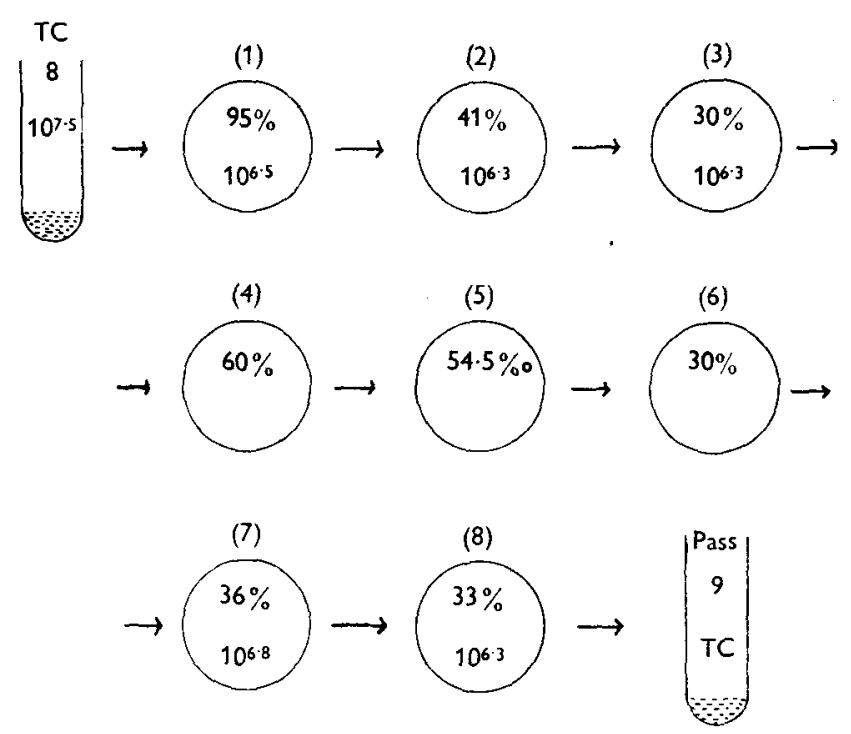

Fig. 2. Mouse-to-mouse passage following the 8th TC-M passage of Mahoney strain. The upper figures in the circles record the percentage of mice paralysed within 4 days of inoculation in each group. The lower figures indicate the virus titres.

very early paralysed mouse, which engendered the adapted variant of the virus, had a titre of $10^{4 \cdot 3} \mathrm{TCID}_{50} / \mathrm{ml}$.

Fig. 2 shows the results of seven mouse-to-mouse passages following the 8th TC-M passage. The incidence of paralysis appearing within 4 days of inoculation dropped from $95 \%$ in the group of mice first inoculated from tissue culture to $33 \%$ 
in the group receiving the 7 th mouse-to-mouse passage. This change in the capacity of the virus to cause paralysis in mice, was, however, accompanied by very little change in tissue culture infectivity, the titre of the brain and cord emulsion being $10^{6 \cdot 5} \mathrm{TCID}_{50} / \mathrm{ml}$. at the beginning and $10^{6 \cdot 3} \mathrm{TCID}_{50} / \mathrm{ml}$. at the end of the series.

Fig. 3 illustrates the results of the first fourteen mouse-to-mouse passages originating from the 9 th $\mathrm{TC}$ which had an infective titre of $10^{5 \cdot 8} \mathrm{TCID}_{50} / \mathrm{ml}$. In this series of passages the tenfold concentrate of brain and cord suspension was used. The incidence of paralysis within 4 days of inoculation was $100 \%$ in the majority of instances, and dropped below $90 \%$ in only two of the earlier groups of mice.

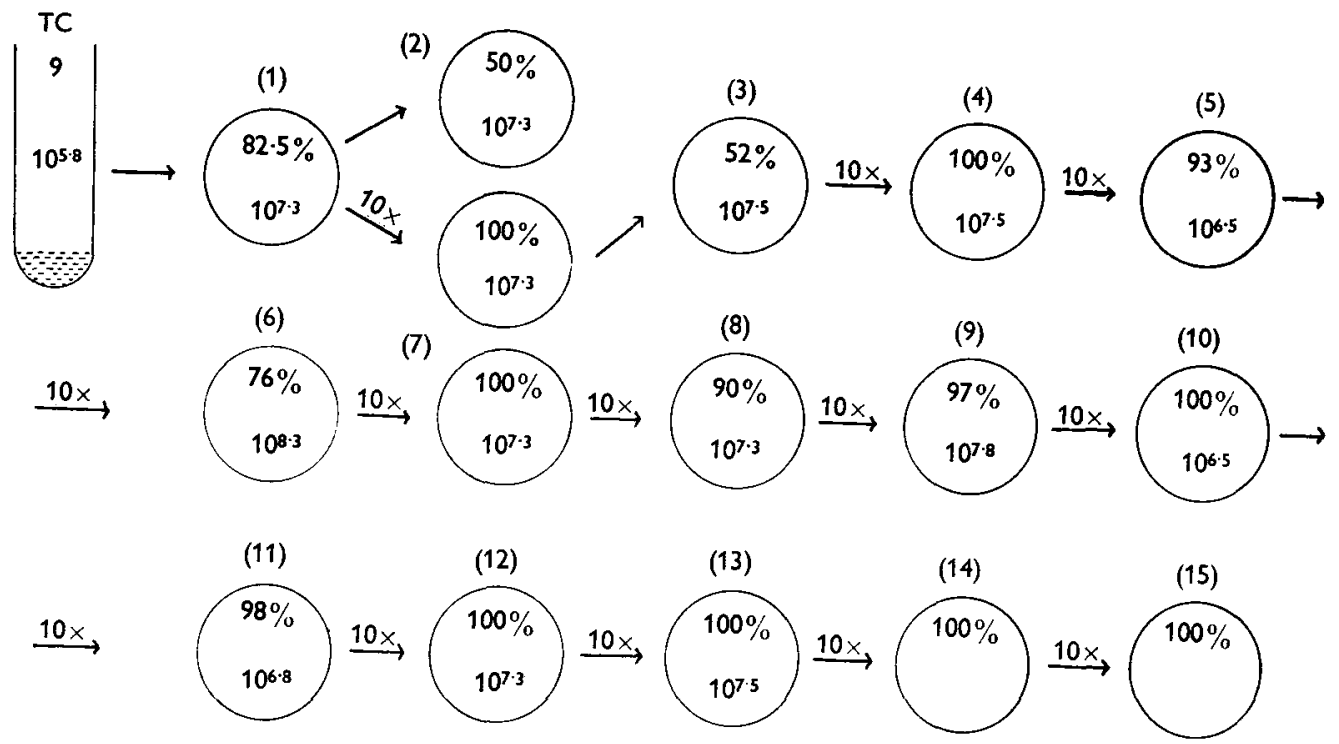

Fig. 3. Mouse-to-mouse passage following the 9th TC-M passage of Mahoney strain. The upper figures in the circles record the percentage of mice paralysed within 4 days of inoculation in each group. The lower figures indicate the virus titres. It will be noted that the inocula for the passages, with the exception of passage 2 , were concentrated tenfold.

From the 15th through to the 75th consecutive mouse-to-mouse passage made to date the concentrated virus suspension was no longer used. Table 1 shows the incidence of paralysis occurring as early as $48 \mathrm{hr}$. after inoculation and also the incidence by the third day, in every 5th passage in this series. The initial drop in the occurrence of paralysis within 2 days may have been due to reversion from the use of concentrate to the usual $10 \%$ suspension as the inoculum. Thereafter with few exceptions the incidence of this very early paralysis has been $80-90 \%$ or higher. The total incidence of paralysis by the third day has been almost invariably $90-100 \%$.

Tests performed throughout the series have demonstrated complete neutralization on testing with Type 1 poliomyelitis monkey immune serum and absence of neutralization with $\mathrm{MEF}_{1}$ Type 2 poliomyelitis mouse immune serum.

Periodic comparisons of the effects of original material, the concentrate, and of the redispersed pellet showed no difference in the incidence of resultant paralysis. 


\section{COMMENT}

It is noteworthy that in the series of seven mouse-to-mouse inoculations following the 8th TC-M passage the incidence of paralysis diminished considerably, but there was almost no alteration in the titre of virus in brain and cord tissues (Fig. 2). There was complete neutralization of each preparation by Type 1 poliomyelitis immune serum, thereby excluding the possibility that part of the infectivity was due to a virus other than Type 1 poliomyelitis virus. The data in Fig. 2 thus appear to confirm the suggestion (Selzer, 1957) that both paralytic and non-paralytic variants of the Mahoney virus were present.

Table 1. Incidence of early paralysis in suckling mice on mouse-to-mouse passage of Mahoney Type 1 poliomyelitis virus

$\begin{array}{cccc}\text { Mouse passage } & \begin{array}{c}\text { No. of mice } \\ \text { inoculated }\end{array} & \overbrace{\text { Within } 48 \mathrm{hr} .}^{\% \text { of mice paralysed }} \\ \mathbf{1 6} & 15 & 66 & \text { Within } 72 \mathrm{hr} \text {. } \\ 20 & 39 & 54 & 87 \\ 25 & 19 & 69 & 82 \\ 30 & 20 & 100 & 94 \\ 35 & 194 & 82 & 90 \\ 40 & 19 & 53 & 100 \\ 45 & 28 & 71 & 79 \\ 50 & 59 & 96 & 98 \\ 55 & 26 & 92 & 100 \\ 60 & 13 & 85 & 92 \\ 65 & 26 & 77 & 96 \\ 70 & 34 & 96 & 97 \\ 75 & 52 & 94 & 96\end{array}$

The titre of virus present in the nervous tissue of the single very early paralysed mouse from which the passage to the 8 th tissue culture was made was notably low, $10^{4 \cdot 3}$, being less than that found in most paralysed sucklings in first-passage groups. From this material, however, the adaptation was finally made. It is suggested that a paralytic variant, capable of growing easily in suckling mice, became prominent. It appears that concentration of the inoculum in the initial mouse-to-mouse passages after 9th TC-M passage encouraged the selective growth of this variant.

A further object in concentrating the material by ultracentrifugation was to remove any possible inhibitor. As there was almost no difference in the incidence of paralysis in comparable experiments using the original brain suspension, and the redispersed virus pellet, the presence of an inhibitor was not demonstrated.

\section{SUMMARY}

The Mahoney, Type 1, poliomyelitis virus had been through six to-and-fro monkey kidney-tissue culture and suckling mouse passages. Early paralysis was produced in groups of mice inoculated directly from infected tissue-culture fluid, but mouseto-mouse passage failed to produce paralysis except in an occasional mouse. At the 7 th tissue-culture mouse passage, the virus harvested from paralysed mice was 
inoculated into 100 mice. One mouse developed paralysis within $24 \mathrm{hr}$. From this mouse a variant of Mahoney virus was isolated which has now been through seventy-five mouse-to-mouse passages and produces paralysis in $90-100 \%$ of mice within 3 days.

The authors would like to express their deep appreciation of Prof. A. Kipps' constant interest and encouragement.

\section{REFERENCES}

Melnick, J. L., Rappaport, C., Banker, D. D. \& Bhatt, P. N. (1955). Stabilized suspension of monkey kidney cells suitable for intercontinental shipment. Proc. Soc. exp. Biol., N.Y., 88,676 .

Selzer, G., SAcks, M. \& VAN Den Ende, M. (1952). Adaptation and multiplication rate of the $\mathrm{MEF}_{1}$ strain of poliomyelitis virus in newborn mice. S. Afr. med. J. 26, 201.

Selzer, G. (1957). Adaptation of Mahoney, Type 1, poliomyelitis virus to suckling mice. J. Hyg., Camb., 55, 374.

(MS. received for publication 10. III. 59) 